\section{POSTOPERATIVE \\ NONINVASIVE VENTILATION \\ IN PATIENTS UNDERGOING \\ CORONARY ARTERY BYPASS \\ GRAFTING: A SMALL STEP \\ WITH GREAT REPERCUSSIONS}

To the Editor:

Commonly, anesthesia, postoperative pain, and surgery induce respiratory modifications (hypoxemia, pulmonary volume decrease, and atelectasis) associated with a restrictive syndrome. ${ }^{1}$ In some cases, postextubation acute respiratory failure is a serious complication after coronary artery bypass grafting. The role of noninvasive ventilation (NIV) in the postoperative period is growing as an alternative therapy to avoid reintubation and associated complications ${ }^{1}$; however, pulmonary complications and NIV interactions still show a complex interaction with preoperative or intraoperative procedures.

In their recent article, Al Jaaly and colleagues $^{2}$ compared 2 strategies in the postoperative period: bilevel positive airway pressure (NIV) and usual care with oxygen therapy. Major findings of this study were that there were no significant differences in intensive care stay, postoperative stay, mean percentage of predicted forced expiratory volume in 1 second on days 1 and 3 , and rate of pulmonary complications (except atelectasis).

We read this original article with interest; however, there are some interesting aspects that were not taken into account and could influence the

\footnotetext{
The Editor welcomes submissions for possible publication in the Letters to the Editor section that consist of commentary on an article published in the Journal or other relevant issues. Authors should: - Include no more than 500 words of text, three authors, and five references. - Type with double-spacing. - See http://jtcs.ctsnetjournals.org/misc/ifora.shtml for detailed submission instructions. - Submit the letter electronically via jtcvs.editorialmanager.com. Letters commenting on an article published in the JTCVS will be considered if they are received within 6 weeks of the time the article was published. Authors of the article being commented on will be given an opportunity of offer a timely response ( 2 weeks) to the letter. Authors of letters will be notified that the letter has been received. Unpublished letters cannot be returned.
}

TABLE 1. Aspects related to atelectasis rate in postoperative surgery

Muscle paralysis

Intravenous or inhalational anesthetics

Body mass index*

Induction of anesthesia (use of a gas mixture) Intraoperative fraction of inspired oxygen $\dagger$

Surgery times

Sedation

*Although obese patients were not included in this
analysis, there is no independent analysis of this factor
between the groups. $\dagger$ This is an important element
because it is associated with a greater reduction in
the proportion of nitrogen and development of
atelectasis. This aspect could explain the worse
response in the group with standard oxygen versus
noninvasive ventilation with respect to a different
fraction of inspired oxygen; the intraoperative aspect
was not evaluated in the study.

interpretation of the outcome. (1) Small numbers of patients were enrolled in both arms of the study, and current smokers should have been grouped separately. Al Jaaly and colleagues ${ }^{2}$ did not describe the preoperative baseline situation, and that is a crucial aspect. ${ }^{3}$ For assessment of postoperative acute respiratory failure, it would be relevant to know the baseline oxygenation index and fraction of inspired oxygen before and after extubation. (2) We do not have information regarding the use of any intraoperative recruitment maneuvers that have shown to have implications for the perioperative period. $^{4}$ (3) Atelectasis rates were clearly different between groups. Atelectasis should be assessed by the radiologist, not the senior clinical team. The atelectasis was diagnosed on clinical basis, and bias may have been a factor. Chest radiography is not sensitive for detection of postoperative atelectasis. There are some factors in the preoperative and postoperative periods that need clarification because they may have influence the results observed ${ }^{5}$; we have summarized them in Table 1. Finally, limited training of the cardiac intensive care unit staff may have influenced the benefit of NIV. NIV was applied intermittently, rather than continuously for few hours.
We consider that further prospective randomized studies will encourage evaluating specific NIV strategies and how intra-operative factors are implicated in postoperative pulmonary complications, especially atelectasis.

Antonio M. Esquinas, MD, PhD, FCCP, International Fellow AARC ${ }^{a}$ Harry Gill, RRT-NPS, RPFT, RN Bushra Mina, MD, FCCP, FACP ${ }^{a}$ Intensive Care Unit Hospital Morales Meseguer Murcia, Spain ${ }^{b}$ Respiratory Therapy Lenox Hill Hospital New York, NY

${ }^{c}$ Pulmonary Critical Care Fellowship Program, Medical Intensive Care Unit, Critical Care Medicine Lenox Hill Hospital New York, $N Y$

\section{References}

1. De Santo LS, Bancone C, Santarpino G, Romano G, Della Corte A, Vicchio $\mathrm{M}$, et al. Noninvasive positive-pressure ventilation for extubation failure after cardiac surgery: pilot safety evaluation. J Thorac Cardiovasc Surg. 2009;137:342-6.

2. Al Jaaly E, Fiorentino F, Reeves BC, Ind PW, Angelini GD, Kemp S, et al. Effect of adding postoperative noninvasive ventilation to usual care to prevent pulmonary complications in patients undergoing coronary artery bypass grafting: a randomized controlled trial. J Thorac Cardiovasc Surg. 2013;146:912-8.

3. Polese G, Lubli P, Mazzucco A, Luzzani A, Rossi A. Effects of open heart surgery on respiratory mechanics. Intensive Care Med. 1999;25: 1092-9.

4. Celebi S, Köner O, Menda F, Korkut K, Suzer K, Cakar N. The pulmonary and hemodynamic effects of two different recruitment maneuvers after cardiac surgery. Anesth Analg. 2007;104: 384-90.

5. Hedenstierna G, Rothen HU. Atelectasis formation during anesthesia: causes and measures to prevent it. J Clin Monit Comput. 2000;16: 329-35.

http://dx.doi.org/10.1016/ j.jtcvs.2013.06.053

\section{Reply to the Editor:}

We thank Esquinas and colleagues for their interest in our article and for their comments. They make 3 points. (1) Our trial was small and did not include any subgroup analyses, in 
particular, current smokers versus former smokers and lifetime nonsmokers. (2) Information on intraoperative recruitment maneuvers was not reported. Such maneuvers may have implications during the perioperative period. (3) Atelectasis was diagnosed clinically and not by a radiologist, and possible influences of preoperative and postoperative factors were not taken into account. We have responses to these points.

First, our trial was randomized. This created intervention and control groups that were balanced with regard to demographic, anthropometric, and respiratory factors. Randomization does not rule out effect modification (point 1); however, it does ensure that an overall treatment effect is not biased (point 3).

Second, subgroup analyses are controversial. International guidelines focus on prespecified subgroup analyses to avoid selective reporting. ${ }^{1}$ Our trial was not powered to detect subgroup effects, and we did not specify any in advance other than preoperative chronic obstructive pulmonary disease (we originally aimed to stratify by chronic obstructive pulmonary disease, but there were insufficient patients with this comorbidity). If we were to carry out subgroup analyses, the findings would be very difficult to interpret. Failure to demonstrate statistical significance might well be due to low power, whereas observation of statistical significance might well be due to chance. For example, Esquinas and colleagues mention the potential influence of body weight: 17 patients with body mass index greater than $30 \mathrm{~kg} / \mathrm{m}^{2}$ had bilevel positive airway pressure, whereas 17 had usual care.

Third, our trial was designed pragmatically to estimate the effect of bilevel positive airway pressure in a real-life setting. Noninvasive ventilation was applied for a median of 11 hours. In the trial, as in usual care, "lung recruitment" (point 2) typically constituted lung reexpansion and the application of positive endexpiratory pressure. Assessment of atelectasis by the senior clinical team was also pragmatic (point 3). From a specialist respiratory perspective, such assessment might be considered insensitive; however, it reflected accurately the information on which management decisions are made in practice. Moreover, we did show a substantial difference in atelectasis frequency; better sensitivity would be expected to increase, not decrease, the observed difference.

Finally, we would like to point out that their summary of the findings of our trial ignores our primary outcome (prespecified in our analysis plan) and our explanation of the reason for failing to observe differences between groups in predicted forced expiratory volume in 1 second and other outcomes that one would expect to differ. As we acknowledged and tried to explain in the article, we had expected the respiratory outcomes to parallel the clinical ones. Because this expectation was not met, we recommended a larger multicenter trial at the end of our Discussion section. This is one point on which we agree. Just as one swallow doesn't make a summer, one trial by itself very rarely brings about (or warrants) a change in practice. We recommended that a larger multicenter, randomized trial of bilevel positive airway pressure be carried out to decide whether the promise suggested in our trial can be substantiated.

Emad Al Jaaly, MD, MRCS ${ }^{a}$ Francesca Fiorentino, PhD, MSc, $B S c^{b}$

Barnaby C. Reeves, MSc, DPhil ${ }^{c}$ Philip W. Ind, MA, FRCP

Gianni D. Angelini, MD, MCh, FRCS, FETCS, FMedSci $i^{b}$ Scott Kemp, MBBS, BSc, FRCA Robert J. Shiner, MRCS, FRCP ${ }^{d}$ ${ }^{a}$ Cardiothoracic Surgery Hammersmith Hospital Imperial College NHS Trust London, UK
${ }^{b}$ Cardiothoracic Surgery

National Heart and Lung Institute Hammersmith Hospital Imperial College London, UK

${ }^{c}$ Clinical Trials and Evaluation Unit University of Bristol Bristol Royal Infirmary Bristol, UK

${ }^{d}$ Respiratory Department National Heart and Lung Institute Hammersmith Hospital Imperial College London, UK

${ }^{e}$ Department of Anaesthesia Hammersmith Hospital Imperial College NHS Trust London, $U K$

\section{Reference}

1. Schulz KF, Altman DG, Moher D, CONSORT Group. CONSORT 2010 statement: updated guidelines for reporting parallel group randomized trials. Ann Intern Med. 2010;152:726-32.

\section{http://dx.doi.org/10.1016/} j.jtcvs.2013.07.004

\section{MITRAL VALVE REPLACEMENT IN THE PRESENCE OF MASSIVE CALCIFICATION}

To the Editor:

I was pleasantly surprised to read the novel technique reported by Hussain and colleagues. ${ }^{1}$ I reported on the technique used at the All India Institute of Medical sciences way back in $1988,{ }^{2}$ which my group used when confronted with a heavily calcified mitral annulus. We used a piece of autologous pericardium to cover the raw surface of the brittle and sandy remnant after limited débridement of calcium and to prevent calcific emboli. This patient was followed up and seen again in 2001, at which time I reported the favorable result of 13 years free of embolism. ${ }^{3} \mathrm{He}$ was last seen in 2009 and was well. Others ${ }^{4}$ have also reported the successful use of this technique. 